\title{
Extended compatibility of fentanyl and ketamine in dextrose $5 \%$
}

\author{
Suci Hanifah', Ross A. Kennedy², Patrick A. Ball ${ }^{3}$ \\ ${ }^{1}$ Department of Pharmacy, Faculty of Science, Universitas Islam Indonesia, Yogyakarta, Indonesia \\ ${ }^{2} S$ chool of Biomedical Sciences, Faculty of Science, Charles Sturt University, Wagga Wagga, Australia \\ ${ }^{3}$ School of Pharmacy, Faculty of Science and Engineering, University of Wolverhampton, United Kingdom
}

\begin{abstract}
Background: There are no published studies that report on fentanyl and ketamine compatibility in dextrose $5 \%$ solution as commonly practiced in hospital settings.

Methods: This study assessed the compatibility of fentanyl and ketamine after their reconstitution in dextrose 5\% under ambient temperature and humidity conditions in a hospital setting. Each sample of fentanyl and ketamine was prepared in triplicate by adding dextrose $5 \%$ to a prefilled syringe until final concentrations of $9.8 \mu \mathrm{g} \mathrm{mL}^{-1}$ for fentanyl and $192 \mu \mathrm{g} \mathrm{mL}^{-1}$ for ketamine were achieved. The solutions were stored in syringes at an ambient temperature ranging $26-28^{\circ} \mathrm{C}$ either under_a mixture of daylight and ambient lighting. A sample was taken from the syringes at the following times: $0,8,24,72,120$, and 168 hours. The samples from each solution were checked for physical changes, $\mathrm{pH}$ and their concentration assessed by high-performance liquid chromatography.

Results: The solutions were clear and no physical changes were seen. The $\mathrm{pH}$ of fentanyl and ketamine decreased dramatically after 72 hours. The concentrations of fentanyl remained $90-110 \%$ only for 24 hours, while ketamine remained $90-110 \%$ for 168 hours.
\end{abstract}

Conclusion: Solutions of fentanyl and ketamine in dextrose $5 \%$ may be used in prefilled syringes only up to 24 hours and 72 hours after reconstitution, respectively.

Anaesthesiology Intensive Therapy 2018, vol. 50, no 3, 221-225

Key words: compatibility, fentanyl, ketamine, reconstitution, syringe

Fentanyl and ketamine are the commonly used analgesic agents in intensive care units [1]. They are widely used as solutions administered by slow continuous infusion in order to achieve an accurate dose [2]. This dilution of medicine may alter the compatibility and stability of the original formulation [3]. However, the common published data sources are often not suitable for conditions in hospitals. The available information on the compatibility and stability of fentanyl and ketamine after reconstitution, were based on dilution in normal saline (NS) and (sterile) water for injection (WFI) [4-7]. However, in hospital environments, fentanyl and ketamine may be given diluted in dextrose or glucose solutions, particularly in patients with hypoglycaemia or sodium restriction.

Compatibility data based on the conditions of hospital practice should be developed [8]. This study investigated the extended compatibility of fentanyl and ketamine diluted in dextrose $5 \%$ under an ambient temperature. This will identify whether the routine work for the most frequent reconstitution of fentanyl and ketamine is safe in terms of compatibility. In addition, these compatibility data will suggest the possible repackaging of fentanyl and ketamine in the centralised intravenous services. Therefore, the current study has addressed a knowledge gap in the compatibility data which is relevant for practice in the ICU and for the development of hospital pharmacy practice.

\section{METHODS \\ DESIGN STUDY}

This study was designed to evaluate the physical and chemical compatibility and stability of fentanyl and ketamine after reconstitution in dextrose $5 \%$ solution, and storage under ambient conditions in a hospital setting. All drugs were diluted with dextrose $5 \%$ solution in $50 \mathrm{~mL}$ 
syringes and were assessed in triplicate. The samples were drawn at zero (0) hours, eight (8) hours, 24 hours, 48 hours, 96 hours and 168 hours for visual inspection, measuring $\mathrm{pH}$ and their concentrations assessed by high pressure liquid chromatography (HPLC).

\section{PREPARATION OF TEST SOLUTIONS}

Fentanyl and ketamine were obtained from manufacturers commonly used in Indonesian hospitals; fentanyl from Janssen Pharmaceutical, Belgium and ketamine from Combiphar, Indonesia. The dextrose $5 \%$ solution was obtained from Widatra, Sidoarjo, Indonesia. The medications were assessed at the concentrations typically used in an intensive care unit. Three sets of each medication solutions were prepared for analysis. The solutions were prepared by measuring (by syringe) the required volume of each drug solution into a $50 \mathrm{~mL}$ volumetric flask and then making it up to a volume with a dextrose $5 \%$ solution. The reconstituted medications were stored in $50 \mathrm{~mL}$ syringes in an open room under ambient light, temperature and humidity. Room temperature and humidity were monitored during experimentation and were within the ranges of $25-28^{\circ} \mathrm{C}$ and $70-80 \%$ relative humidity $(\mathrm{RH})$. Five-millilitre $(\mathrm{mL})$ samples were drawn for visual inspection and $\mathrm{pH}$ measurement, while a $1 \mathrm{~mL}$ sample was taken for HPLC assay at each sampling time.

\section{PREPARATION OF STANDARD SOLUTIONS AND STANDARD CURVE}

The stock solutions were prepared for the validation procedures on assessment days 1, 3, and 7. Standard solutions for both drugs were prepared at relevant concentrations from initial stock solutions of $1 \mathrm{mg} \mathrm{mL}^{-1}$ in dextrose $5 \%$ aqueous solutions.

\section{PHYSICAL COMPATIBILITY: VISUAL INSPECTION}

Judgment of compatibility follows the outline shown in Figure 1. Physical compatibility was visually evaluated to assess clarity, colour changes and gas formation. The observations were made independently by two people using a black background and a white background under fluorescent light. Clarity and gas formation was observed against a black background to demonstrate haziness, precipitation, or bubbles, while colour changes were more easily determined against a white background. The solution was considered incompatible physically if any presence of discoloration, haziness, precipitation or gas formation was visible.

\section{CHEMICAL COMPATIBILITY: PH AND CHROMATOGRAPHY ASSAY}

The $\mathrm{pH}$ measurements utilised a calibrated $\mathrm{pH}$ meter, namely a Mettler Toledo 1120/1120-X (Urdorf, Switzerland).
The $\mathrm{pH}$ level was measured by dipping a $3 \mathrm{~mL}$ sample solution into the cuvette until the $\mathrm{pH}$ meter displayed the $\mathrm{pH}$ level. A change in $\mathrm{pH}$ of more than a half unit during the measurement period or a shift of $\mathrm{pH}$ beyond the usual range specified by the manufacturer was taken as indicative of incompatibility.

Concentration analyses employed a high pressure liquid chromatography (HPLC) apparatus, namely the e2695 Waters Associates (Milford, MA, USA) equipped with an Xterra MS C18 column, $5 \mu \mathrm{m}, 4.6 \times 250 \mathrm{~mm}$. The mobile phase and the water were HPLC grade without previous purification. The two mobile phases were HPLC grade obtained from Merck, Darmstadt, Germany. They comprised a phosphate buffer containing monopotassium dihydrogen phosphate $\left(\mathrm{KH}_{2} \mathrm{PO}_{4}\right)(0.05$ molar; $\mathrm{pH} 4$.2) in HPLC water and acetonitrile. Each drug was assayed separately at the wavelength of maximum absorbance ( $\lambda$ max), that is ketamine in $210 \mathrm{~nm}$ and fentanyl in $280 \mathrm{~nm}$. The samples were introduced into the HPLC system using an auto sampler injector, namely an SM 7, 2489 UV/Vis detector, at a solvent flow rate of $1 \mathrm{~mL} \mathrm{~min}-1$ and an injection volume of $10 \mu \mathrm{L}$. A reduction of the concentration to less than $90 \%$ of the value at time zero (0) was considered unacceptable or chemically incompatible (see Fig. 1).

\section{RESULTS}

The results of validation are given in Table 1. Linearity of concentration under the curve (AUC) was demonstrated by linear regression after five different dilutions. The standard curves were linear $(r 2 \geq 0.99$ ) over the assessment days. Accuracy was determined by preparing a target concentration, injecting the solution and predicting the concentration from the linear regression data achieving a range 95-10\%. Precision was assessed by measuring the concentrations of five replicate dilutions. The intraday and interday coefficients of variation ranged $\leq 2.25 \%$, and $\leq 3.5 \%$ respectively. Concentration was used to analyse concentration change. The retention times for the four drugs were less than 20 minutes. The blank sample of dextrose $5 \%$ solution showed no peaks during 30 minutes. The chromatograms are considered suitable if the symmetry factor is less than 1.5: with a USP plate count efficiency at $n>2,000[9,10]$.

Visual observation showed that fentanyl and ketamine after reconstitution were physically compatible during seven days of storage. No turbidity, gas, colour changes or precipitation were observed during 168 hours of storage.

The $\mathrm{pH}$ changes of fentanyl and ketamine are shown in Figure 2; fentanyl ( $\mathrm{DpH}=-0.99 \mathrm{pH}$ unit) and ketamine (DpH $=-1.69 \mathrm{pH}$ unit). Fentanyl and ketamine showed a significant $\mathrm{pH}$ drop after 72 hours: the $\mathrm{pH}$ value at 120 hours of fentanyl was 3.37 while for ketamine, this was 3.34. The $\mathrm{pH}$ 


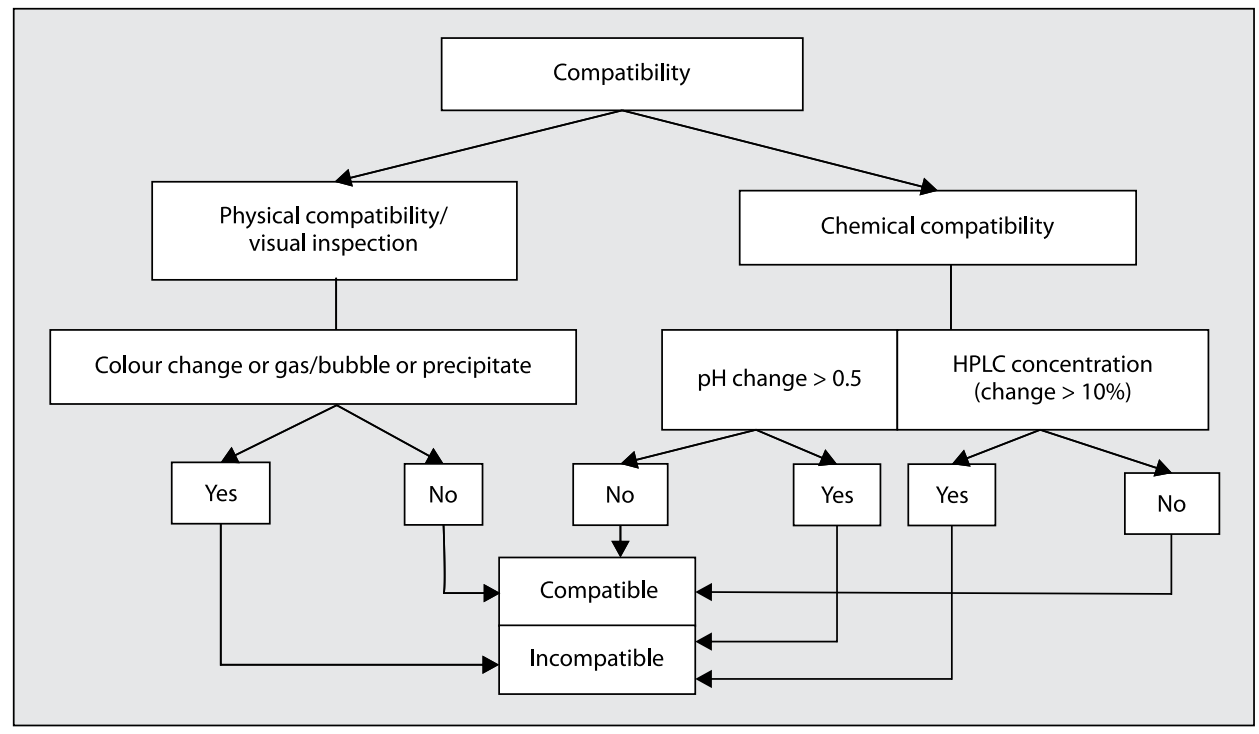

Figure 1. Criteria of incompatibility

Table 1. Validation of fentanyl and ketamine on HPLC system

\begin{tabular}{|c|c|c|c|c|c|c|c|c|c|c|c|}
\hline \multirow[t]{2}{*}{$\begin{array}{l}\text { Sample } \\
\text { added } \\
\text { concentration }\end{array}$} & \multirow[t]{2}{*}{$\begin{array}{l}\text { Retention } \\
\text { time }\end{array}$} & \multicolumn{2}{|c|}{$\begin{array}{l}\text { R Value } \\
\text { (regression } \\
\text { logistic) }\end{array}$} & \multicolumn{2}{|c|}{ Initial concentration } & \multicolumn{2}{|c|}{$\begin{array}{c}\text { \% Accuracy } \\
\left(C_{v}\right)\end{array}$} & \multicolumn{2}{|c|}{$\begin{array}{c}\text { \% RSD } \\
\text { Intra-day }\end{array}$} & \multicolumn{2}{|c|}{$\begin{array}{c}\text { \% RSD } \\
\text { Inter-day }\end{array}$} \\
\hline & & Height & Area & Height (\%)* & Area $(\%)^{*}$ & Height* & Area* & Height & Area & Height & Area \\
\hline $\begin{array}{l}\text { Fentanyl } \\
9.8 \mu \mathrm{gL}^{-1}\end{array}$ & 3.2 & 0.99 & 0.99 & $\begin{array}{c}10.57 \mu \mathrm{g} \mathrm{mL}^{-1} \\
(107.85 \%)\end{array}$ & $\begin{array}{c}10.09 \mu \mathrm{g} \mathrm{mL}^{-1} \\
(102.96 \%)\end{array}$ & $\begin{array}{l}101.71 \\
(0.65)\end{array}$ & $\begin{array}{l}96.53 \\
(1.46)\end{array}$ & 0.67 & 0,30 & 0.42 & 0.93 \\
\hline $\begin{array}{l}\text { Ketamine } \\
192 \mu \mathrm{q} \mathrm{mL} \mathrm{m}^{-1}\end{array}$ & 3.5 & 0.99 & 0.99 & $\begin{array}{c}198.61 \mu \mathrm{g} \mathrm{mL}^{-1} \\
(103.44 \%)\end{array}$ & $\begin{array}{c}203.12 \mu \mathrm{g} \mathrm{mL}^{-1} \\
(105.79 \%)\end{array}$ & $\begin{array}{c}102.10 \\
(0.73)\end{array}$ & $\begin{array}{l}98,32 \\
(0.98)\end{array}$ & 0.62 & 2.25 & 3.13 & 1.02 \\
\hline
\end{tabular}

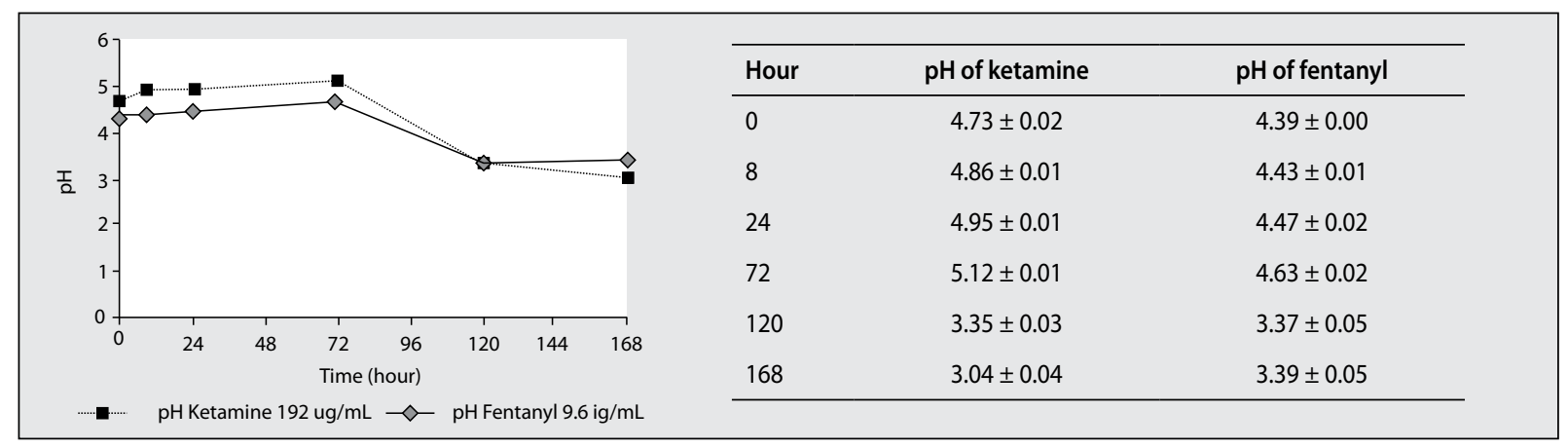

Figure 2. Changes in $\mathrm{pH}$ of fentanyl and ketamine diluted in dextrose $5 \%$ solution under ambient temperature and light exposure during seven days

of fentanyl and ketamine decreased outside the usual range of $\mathrm{pH}$ as stated by the manufacturers.

Furthermore, chemical compatibility was also evaluated with the percentage of concentration seen as the degradation of a height and area chromatogram. As shown on Figure 3, the percentage degradation of ketamine was within an acceptable range of $\geq 90 \%$ for 196 hours observation (seven days), even though the $\mathrm{pH}$ was normal only over 72 hours. Moreover, fentanyl re- tained $99 \%$ concentration for 24 hours, but then dropped to $75 \%$ at 72 hours.

\section{DISCUSSION}

The current study showed that using a dextrose $5 \%$ solution for reconstitution, both drugs, namely fentanyl and ketamine, were compatible for 24 hours under conditions typical for an intensive care unit. However, storage for longer than 24 hours is questionable. 


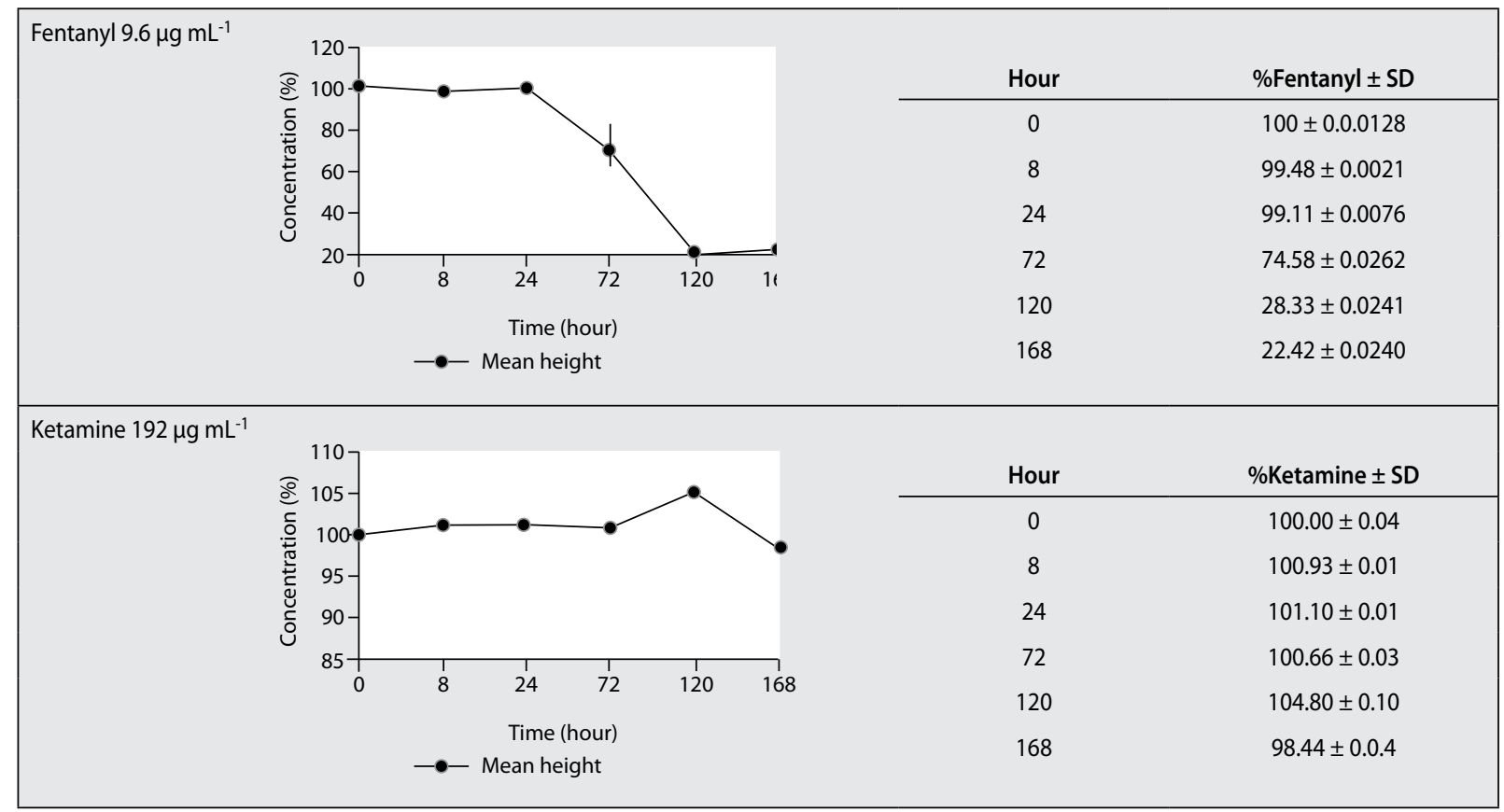

Figure 3. Changes in concentration of fentanyl and ketamine diluted in dextrose $5 \%$ solution under ambient temperature and light exposure during seven days

The striking increase of the ketamine concentration at 120 hours was predicted since there is an initial degradation process, the products of which were not effectively separated using this method. This degradation may be caused by an oxidation reaction. In the initiation phase, this reaction decreases the $\mathrm{pH}$ following free radicals which emerge and react, before finally the concentration drops due to the degradation products. This was seen in the $\mathrm{pH}$ value that declined considerably after 72 hours. Thus, ketamine would not be considered to be chemically compatible in a dextrose $5 \%$ solution for $\geq 72$ hours. Although ketamine had concentration in a range $90-110 \%$, the $\mathrm{pH}$ dropped significantly after 72 hours. In theory, the decrease of 1.69 $\mathrm{pH}$ units will change the ionization level up to 50 fold. To the best of the author's knowledge, no other study has reported on the compatibility of ketamine in this vehicle (i.e. dextrose $5 \%$ solution). However, the compatibility data in the other vehicle (i.e. WFI) was stable for 30 days at room temperature and exposed to light [4], and even longer (182 days) in normal saline (NS) and WFI [5].

A word of warning needs to be given with regard to fentanyl. In the current study, although fentanyl had higher than $90 \%$ concentration at 24 hours, this decreased to $75 \%$ concentration at 72 hours. This change was also supported with the $\mathrm{pH}$ dropping after 72 hours, as with ketamine. The interpolated results for fentanyl showed $90 \%$ concentration for 28 hours. This showed that reconstituted fentanyl in dextrose $5 \%$ solution must be administered immediately after preparation.
This study found a faster degradation rate compared with that found in other research, such as by Kowalski who found that fentanyl retained $95 \%$ concentration for 48 hours, but under WFI [11]. Using similar conditions (room temperature and light exposure), Roos et al. [12] showed that fentanyl diluted in NS retained $87 \%$ concentration at 30 hours. However, there are no publications that used a similar dilution in dextrose $5 \%$.

Furthermore, although the stability of fentanyl in dextrose $5 \%$ solution is short, there is evidence that the stability of fentanyl increases when it is diluted in normal saline (NS) or (sterile) water for injection (WFI) $[6,7]$. The stability of fentanyl can be prolonged up to 30 days after reconstitution using normal saline (NS). Ketamine injection can also retain $90 \%$ concentration for a longer time (30 days) when diluted in WFI [13] and up to 12 months in NS [14]. Thus, this study suggests that hospital staff should reconstitute fentanyl and ketamine in dextrose $5 \%$ immediately prior to use. However, it is safer to consider changing the reconstitution solution to NS or WFI for these drugs, if appropriate for patient.

As this research aimed to validate the routine work done in hospitals, the circumstances and the materials were applied according to hospital conditions. Different conditions in other hospitals may alter the compatibility data.

\section{CONCLUSIONS}

At the same concentration and in similar conditions (ambient temperature and light exposure) these findings 
indicate that ketamine in dextrose $5 \%$ is compatible for administration in the ward for 72 hours. In contrast, hospital should issue warnings about the reconstitution of fentanyl in dextrose $5 \%$, as it is safe only for 24 hours.

\section{ACKNOWLEDGMENTS}

1. The authors would like to thank to the Ministry of Research Technology and Higher Education (KEMENRISTEK DIKTI) of Indonesia for making this research possible.

2. Source of funding: none.

3. Conflict of interest: none.

\section{References:}

1. Celis-Rodríguez E, Birchenall C, de la Cal MÁ, et al. Federación Panamericana e Ibérica de Sociedades de Medicina Crítica y Terapia Intensiva. Clinical practice guidelines for evidence-based management of sedoanalgesia in critically ill adult patients. Med Intensiva. 2013; 37(8): 519-574, doi: 10.1016/j.medin.2013.04.001, indexed in Pubmed: 23773859.

2. Maciejewski D. Sufentanil in anaesthesiology and intensive therapy. Anaesthesiol Intensive Ther. 2012; 44(1): 35-41, indexed in Pubmed: 23801512.

3. Hoellein L, Holzgrabe U. Ficts and facts of epinephrine and norepinephrine stability in injectable solutions. Int J Pharm. 2012; 434(1-2): 468-480, doi: 10.1016/j.ijpharm.2012.05.017, indexed in Pubmed: 22613065.

4. Gupta VD, Stewart K. Stability of dobutamine hydrochloride and verapamil hydrochloride in $0.9 \%$ sodium chloride and $5 \%$ dextrose injections. Am J Health-System Pharm. 1984; 41(4): 686-689, doi: 10.18578/bnf.111880283.

5. Donnelly RF. Stability of diluted ketamine packaged in glass vials. Can J Hosp Pharm. 2013; 66(3): 198, indexed in Pubmed: 23814289.
6. Allen $\mathrm{L}$, Stiles $\mathrm{M}$, Tu YH. Stability of fentanyl citrate in $0.9 \%$ sodium chloride solution in portable infusion pumps. Am J Health-System Pharm. 1990; 47(7): 1572-1574.

7. McCluskey SV, Graner KK, Kemp J, et al. Stability of fentanyl 5 microg/ $/ \mathrm{mL}$ diluted with $0.9 \%$ sodium chloride injection and stored in polypropylene syringes. Am J Health Syst Pharm. 2009; 66(9): 860-863, doi: 10.2146/ajhp080255, indexed in Pubmed: 19386950.

8. Hanifah S. Mapping of incompatibility assay: bringing method to problem in critical care. Int J Pharm Pharmaceut Sci. 2014; 6(4): 171-173.

9. Dong M, Gershanov P, Gershanov L. Getting the peaks perfect: system suitability for HPLC. Todays Chemist at Work. 2001; 10(9): 38-34.

10. Dolan JW. Why do peaks tail? LCGC Eur. 2003; 21(7): 610-613.

11. Kowalski S, Gourlay G. Stability of fentanyl citrate in glass and plastic containers and in a patient-controlled delivery system. Am J Health-System Pharm. 1990; 47(7): 1584-1587.

12. Roos PJ, Glerum JH, Meilink JW. Stability of sufentanil citrate in a portable pump reservoir, a glass container and a polyethylene container. Pharmaceutisch Weekblad Scientific Edition. 1992; 14(4): 196-200, doi: 10.1007/bf01962538.

13. KiserTH, Oldland AR, Fish DN. Stability of phenylephrine hydrochloride injection in polypropylene syringes. American Journal of Health-System Pharmacy. 2007; 64(10): 1092-1095, doi: 10.2146/ajhp060139.

14. Stucki M. Development of ready-to-use ketamine hydrochloride syringes for safe use in post-operative pain. Eur J Hosp Pharm Sci . 2008; 14(1): 14-18.

\section{Corresponding author:}

Suci Hanifah

Department of Pharmacy, Faculty of Science,

Universitas Islam Indonesia

Jalan Kaliurang km 14.5 Sleman DI. Yogyakarta 55582

e-mail: suci.hanifah@uii.ac.id

Received: 14.04 .2018

Accepted: 13.06.2018 